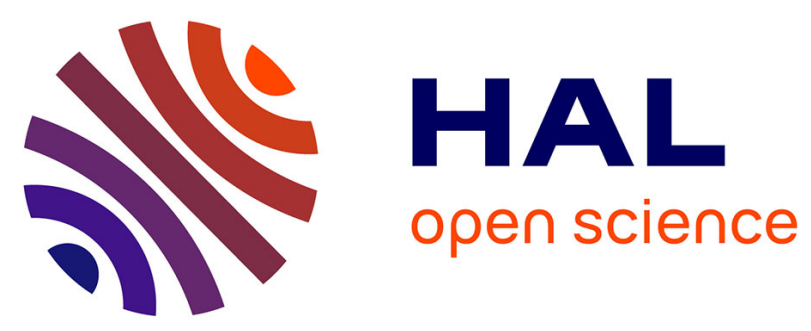

\title{
Subliminal Priming of Motivational Orientation in Educational Settings: Effect on Academic Performance Moderated by Mindfulness
}

Rémi Radel, Philippe Sarrazin, Pascal Legrain, Lucie Gobancé

\section{- To cite this version:}

Rémi Radel, Philippe Sarrazin, Pascal Legrain, Lucie Gobancé. Subliminal Priming of Motivational Orientation in Educational Settings: Effect on Academic Performance Moderated by Mindfulness. Journal of Research in Personality, 2009, 43, pp.695-698. 10.1016/j.jrp.2009.02.011 . hal-00390355

\section{HAL Id: hal-00390355 https://hal.science/hal-00390355}

Submitted on 2 Jun 2009

HAL is a multi-disciplinary open access archive for the deposit and dissemination of scientific research documents, whether they are published or not. The documents may come from teaching and research institutions in France or abroad, or from public or private research centers.
L'archive ouverte pluridisciplinaire HAL, est destinée au dépôt et à la diffusion de documents scientifiques de niveau recherche, publiés ou non, émanant des établissements d'enseignement et de recherche français ou étrangers, des laboratoires publics ou privés. 
Running head: MODERATION OF PRIMED MOTIVATION BY MINDFULNESS

Subliminal Priming of Motivational Orientation in Educational Settings:

Effect on Academic Performance Moderated by Mindfulness

Rémi Radel $^{1}$, Philippe Sarrazin ${ }^{1}$, Pascal Legrain ${ }^{2}$, Lucie Gobancé ${ }^{2}$

${ }^{1}$ University of Grenoble, ${ }^{2}$ University of Reims

Authors' note: We particularly thank Lisa Mask for valuable comments on this manuscript.

Correspondence concerning the article should be addressed to Rémi Radel or Philippe Sarrazin,

Laboratoire SENS, Université de Grenoble, BP 53, 38041 Grenoble Cedex 9, France. E-mail:

remi.radel@e.ujf-grenoble.fr, philippe.sarrazin@ujf-grenoble.fr 


\begin{abstract}
Recent literature indicates that a motivational orientation can be unconsciously primed. This study examined whether motivational priming influences students' academic performance within an educational setting and whether this effect is moderated by students' degree of mindfulness. Two randomly assigned groups of students received an identical lesson. However, the teacher's slideshow contained different subliminal words according to the condition (autonomous vs. controlled motivation). Results demonstrated an interaction between students' dispositional mindfulness and priming conditions. The more mindful students were immune to the manipulation whereas the less mindful students were affected by the priming: those primed with autonomous motivation obtained better results than those primed with controlled motivation. These findings contribute to priming research specifying individual differences of priming responsiveness.
\end{abstract}

Keywords: autonomous motivation; controlled motivation; mindfulness; priming 
Research devoted to automaticity and non-conscious processes has exploded over the last years. Evidence from this body of literature indicates that people tend to assimilate the content of environmental stimuli they perceive in an automatic fashion (Bargh, 2006). More precisely, cognitive representations could be temporarily activated - a procedure known as priming outside of awareness, to influence subsequent perception and behavior in prime consistent directions. Priming has been successfully used to activate traits, attitudes, and stereotypes (see Hassin, Uleman, \& Bargh, 2005, for a review). Even motivational processes, which were long thought to be deliberative and conscious (see Weiner, 1992) have been shown to be triggered by priming (see Ferguson, Hassin, \& Bargh, 2007).

Nevertheless, research on automaticity of motivational processes has focused mainly on concrete goals and less on general motivations. For this purpose, recent studies (Lévesque \& Pelletier, 2003; Hodgins, Yacko, \& Gottlieb, 2006) have investigated whether the two broad motivational orientations postulated by Self-Determination Theory (SDT; e.g., Deci \& Ryan, 2008) - namely, autonomous and controlled motivation- could also be triggered automatically. Individuals are said to be autonomously motivated when they experience their behaviors as freely chosen, emanating from their true selves. In contrast, a controlled motivation is evidenced in those who engage in their behaviors for external or internal pressure. Past research in the educational setting (see Reeve, 2002 for a review) has shown that an autonomous motivation results in better academic performance while a controlled motivation results in negative outcomes for students.

In the Levesque and Pelletier's (2003) study, participants were primed using a supraliminal technique (i.e., individuals consciously perceived the primes but were not aware of their effect) which consisted of constructing sentences from sets of scrambled words that were 
related to either an autonomous (e.g., interested) or a controlled (e.g., constrained) motivation. Participants then solved crossword puzzles in an ostensibly unrelated task. Although participants were unaware of the manipulation, results revealed that those primed with an autonomous motivation displayed higher levels of intrinsic motivation, interest/enjoyment, perceived choice, and performed better than those primed with a controlled motivation. Using the same supraliminal procedure of priming, the Hodgins et al. 's (2006) studies examined whether primed motivational orientations (i.e., autonomous vs. controlled) were related to the use of different defensive behaviors (i.e., intention to avoid some aspect of reality). Their results showed that participants primed with an autonomous motivation reported lower desire for escape, lower selfserving bias, and less self-handicapping than participants primed with a controlled motivation. Together, results of these studies indicate that motivational primes are generally assimilated and result in differential outcomes measured in the laboratory.

To date, no studies have investigated the impact of motivational primes in a natural setting, such as the classroom. Unlike lab settings where stimuli and environmental condition are highly constrained and controlled, educational arena presents many other stimuli that could interfere with the manipulated prime and undermine its effect. Therefore, an important and pending question of priming research is to know whether the priming effect is strong enough to influence individuals in their daily life (Bargh, 2006). Hence, the first aim of this study is to investigate the differential impact of motivational primes on performance in a real-life setting: the classroom.

Another important perspective of the priming research is to examine individual differences in priming responsiveness (Bargh, 2006). In this respect, individual differences in mindfulness (Langer, 1989) could be interesting to investigate. According to Langer's view, 
"mindless" individuals would pay little conscious attention to the present context. Therefore, their current behavior would be largely determined by unconscious processes; blindly following routines or impulses, often acting like automatons. In contrast, "mindful” individuals should turn away from automatic guidance and rely more on deliberate processes. They would carefully evaluate the context in order to determine appropriate ways of behaving in this context.

Mindfulness is thus assumed to be particularly relevant to disrupting automatic influences (Brown \& Ryan, 2003; Langer, 1989). Recently, Lévesque and Brown (2007) demonstrated that mindfulness moderated the effect of implicit motivation on motivation for day-to-day behaviors. Specifically, their findings indicated that implicit autonomy orientation assessed with an implicit measure predicted day-to-day motivation for various activities only for those lower in dispositional mindfulness. Contrary to primed motivation, implicit motivations are chronic (i.e., the mental representation is always highly accessible) and their unconscious nature is less certain (e.g., Fazio \& Olson, 2003). Hence, the second aim of our study is to extend these findings by examining whether students' dispositional mindfulness would moderate the unconscious effect of a temporarily activated motivation using subliminal priming.

To examine our objectives, we randomly divided students to attend one of two regular classes. Different subliminal words were imbedded in the instructors' slideshow depending on the experimental condition. One group of students was exposed to words reflecting autonomous motivation whereas the other was exposed to words reflecting controlled motivation. With exception to the experimental condition, both classes were as identical as possible.

We hypothesized that students primed with an autonomous motivation during the lesson would be more interested and more attentive, and in turn would evidence greater performance on a quiz related to the content of this lesson than students primed with a controlled motivation. We 
also anticipated that mindfulness would moderate the priming effects on performance such that more mindful students would be less influenced by the primes compared to less mindful students.

\section{Method}

\section{Participants}

Eighty-eight French first year undergraduate students (30 female and 58 male; $M=19.4$ \pm 0.7 years) of the University of Reims participated in this study. Students were unaware of their participation in the study until the end of the lesson as informed consent was delayed ${ }^{1}$.

\section{Procedure}

During a mass test session at the beginning of the semester, all students completed a battery of self-report scales including a measure of dispositional mindfulness. At the end of the semester, the same group of students was randomly assigned to two equal groups (autonomous vs. controlled condition). Each one attended a regular psychology class during two separate timeslots on the topic of social relationships development in childhood. Both classes were delivered successively on the same afternoon, in the same lecture hall, by the same teacher. The teacher was a senior lecturer blind to the experimental condition. The entire lesson was scripted, learned, and delivered in total accordance with the script. The total duration of the lesson was 60 minutes. At the end of each lesson, students were quizzed on the content of the lesson. Upon completion of the quiz, students were queried on their awareness of the experimental manipulation (i.e., "Did you notice something special during the lesson?"; "Did you detect an anomaly or a defective element in the slideshow?"; "Was this lesson different from your regular lessons?"). Students were then debriefed by the experimenters who informed them as to the specific aim, the hypotheses and the method of the study. Experimenters ensured that students' 
deception was minimal and permission to use their data for research purposes was obtained. Finally, results of this experiment were presented to students in a subsequent lesson. Experimental manipulation

The instructor's slideshow was modified in order to incorporate subliminal words. The slideshow used for the first timeslot (i.e., "controlled" condition) was labeled "1" while the slideshow used for the second timeslot (i.e., "autonomous" condition) was labeled "2". Each one included 86 primes which were interspersed among the 22 slides. Primes used for the autonomous condition were "interested", "desire", "willing" and "free" while primes used for the controlled condition were "obligation", "constraint", "forced" and "ought"2. These words were chosen according to previous studies using words to depict motivational orientations (e.g., Lévesque \& Pelletier 2003; Lévesque \& Brown, 2007). Subliminal words were randomly displayed in different locations of the slide. According to Bargh and Chartrand's (2000) recommendations, each subliminal word was displayed for $32 \mathrm{~ms}$ followed by a $16 \mathrm{~ms}$ mask

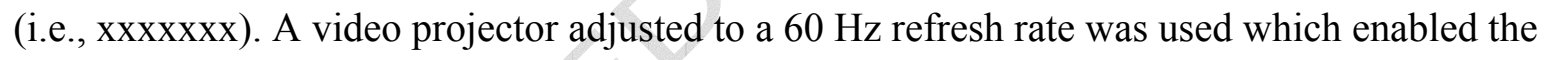
primes to appear as planned.

\section{Measures}

Performance. The quiz was comprised of 13 questions pertaining to the content of the lesson including elements presented both orally by the teacher and visually via the slideshow. Different forms of closed answers were asked (e.g., to complete a definition; to find the correct answer among different suggestions). Two judges blind to each condition marked the quiz (intraclass correlation $=.92$ ) attributing one point for each correct answer. A mean score (ranged from 0 to 13 ) was computed based on the ratings of both judges. 
Regular performance. In order to control for individual differences in regular performance, students' final grades (ranged from 0 to 20) on their comprehensive end of semester exam were obtained.

Mindfulness. Dispositional mindfulness was assessed using a French version of the Mindful Attention Awareness Scale (MAAS, Brown \& Ryan, 2003). Back translation procedures were carried out with two bilingual persons. Two items were removed because they could not be translated without a modification of meaning. An exploratory factor analysis supported the unidimensional structure as the 13 items loaded on a single factor (factor 1 eigenvalue $=3.87$; factor 2 eigenvalue $=.95)$. Nevertheless, two items had factor scores less than .22 and were therefore deleted. The final scale $(\alpha=.85)$ was comprised of 11 items (e.g., "I do jobs or tasks automatically, without being aware of what I'm doing"; "I find myself doing things without paying attention") rated on a 6 point Likert scale ranging from (1) "almost always" to (6) "almost never". Thus, a high score on this scale indicates greater mindfulness.

\section{Results}

Awareness of the manipulation. All the students negatively answered the two first questions indicating that they were unaware of the experimental manipulation and detected no anomaly in the slideshow. In addition, all students perceived this lesson similar to other lessons that they usually receive ( $97.7 \%$ answered "yes" and $2.3 \%$ did not answer).

Main and interaction effects. Means and standard deviations of the main variables as a function of the priming condition are presented in Table 1. Multiple regression analyses were conducted in order to test the differential impact of motivational primes on performance and whether this effect was moderated by dispositional mindfulness. The dependent variable was performance on the quiz. Participants' regular performance, sex, mindfulness, priming conditions 
(coded +1 for autonomous condition and -1 for controlled condition), and all possible double and triple interactions served as predictors. In order to obtain a better adjustment of the model, we proceeded to remove the non-significant variables of the model except if it was a term of a significant interaction.

The overall model, including participants' regular performance, priming conditions, mindfulness and the interaction between mindfulness and priming conditions, was significant $\left[F(4,84)=3.46, p<.01 ; R^{2}=.15\right]$. Conditional main effect analyses evidenced a positive effect of regular performance $(\beta=.26, p<.05)$, and non-significant effects of priming conditions $(\beta=$ $.17, p=.10)$, and mindfulness $(\beta=-.05, p=.63)$. The effect of the interaction term was significant $(\beta=.23, p<.05)$.

In order to further the interpretation of this significant moderating effect, two different procedures were carried out (Aiken \& West, 1991). First, we tested the significance of the slopes for high (1 SD above the mean) and low (1 SD below the mean) mindfulness values. Results indicated that priming condition predicted performance when mindfulness was low $(\beta=.38, p<$ $.05)$ but not when mindfulness was high $(\beta=-.08, n s)$. Figure 1 depicts this aspect of the moderation.

Second, we examined the region of significance using the Johnson Neyman procedure. Results indicate that the priming conditions had a significant effect for all values of the moderator under 2.95. This value is located $0.11 S D$ below the mean score of mindfulness. We determined that 36 students were included in this region. Thus, we can statistically deduce that $41 \%$ of the sample was significantly affected by the priming manipulation. 


\section{Discussion}

The first purpose of this study was to examine the effect of subliminal priming of autonomous versus controlled motivational orientations on performance in a natural setting, namely the classroom. According to past research in SDT (see Reeve, 2002 for a review), it was expected that students primed with an autonomous motivation would perform better on a quiz related to the content of the lesson compared to students primed with a controlled motivation. Results did not support this hypothesis. This null finding is probably due to the larger number of stimuli that naturally exist in the classroom compared to a controlled environment such as the laboratory.

A second aim of this study was to examine individual differences in priming effects using the construct of mindfulness. Given that mindless individuals behave more automatically, we expected that the priming effect would be stronger for such students. Results supported our hypothesis. The less mindful students assimilated the motivational prime and behaved in the same way as if they would have consciously adopted their motivational orientation. According to Self-Determination Theory (Deci \& Ryan, 2008), we assume that students who adopted the primed autonomous motivation were more interested and receptive to the lesson, which in turn resulted in better performance than students who assimilated the controlled motivation primes. However, these effects were not found among those who were more mindful. These findings are congruent with those of Lévesque and Brown (2007), who found that the behaviors of their more mindful participants were not sensitive to another form of automatic motivation.

This suggests that mindfulness enables students to exert control over the influence of primes. The subliminal words surely made the primed motivational orientation just as accessible in more mindful students but the processing of information would be more reflexive and less 
automatic. Thus, mindful students probably discounted the primed motivational orientation when it was not appropriate. Unlike mindless individuals, mindful people actively think about what they are going to do in the present context and why they do what they do (Brown \& Ryan, 2003). Thus, this variable seems to be a relevant defensive mechanism for controlling the negative impulses of environmental priming allowing people to act more in accordance with their personal goals and desires. Nevertheless, an interesting perspective would be to determine whether this defensive aspect of mindfulness could have a pernicious side. Figure 1 shows that the more mindful students did not benefit from even the autonomous primes. Perhaps highly mindful individuals may be too self-referenced to take advantage of positive elements in the environment. Future studies might envisage this puzzling question.

We think that findings of this study can yield important implications for the educational milieu. Our results indicate that a subliminal technique could be used to increase autonomous motivation of certain students. Nevertheless, we think that applications should not be based on the direct use of this technique in the classroom or other audience context. Subliminal priming greatly serves research purposes but it should not be used in applied settings until many ethical concerns have been clearly deliberated (see Dijksterhuis, Aarts, \& Smith, 2005). Our results can however be extended to supraliminal primes (i.e., consciously perceived) which generate the same effect as long as individuals are not aware of the influence of the primes (Dijksterhuis et al., 2005). Motivational priming is therefore relevant in the educational context, as many supraliminal primes can exist in the classroom. Recent findings have indeed showed that natural cues can elicit a motivational orientation. For example, merely hearing the voice of motivated person without consciously paying attention was sufficient to affect participants' motivation (Radel, Sarrazin, \& Pelletier, 2008). In a learning context, Wild, Enzle, Nix and Deci (1997) 
have shown that merely perceiving cues related to the instructor's motivation influenced students' motivation. In sum, these multiple sources of priming present in natural settings can lead to new ways to act upon individuals' motivation. For example, educators might utilize primes by laying them out in their environment (e.g., displaying material containing motivational elements; expressing explicitly their own interest). In addition, these strategies based on unconscious processes might be the only way to increase motivation of mindless students as these individuals could not be very sensitive to motivational strategies based on conscious processes (e.g., providing rationale, goal setting). Further studies are needed to investigate these questions.

\section{Conclusion}

In his seminal article, Bargh (2006) envisioned perspectives of priming research. Observing that this research has now provided reliable evidence of the priming effects with many different psychological processes, Bargh expressed the need to move toward a new category of investigations, namely the "second generation questions" such as investigating whether priming still works in natural complex environment, and identifying individual differences in priming effectiveness. In this study, we reported the presence of a partial effect of priming in a real-life educational setting where primes were imbedded in other stimuli of the social environment. More precisely, the priming effect depended on the degree of mindfulness of the individuals. Taken together, we think that findings from this study yield a first answer to these second generation questions, helping to clarify conditions under which priming effects occur. 


\section{References}

Aiken, L. S., \& West, S. G. (1991). Multiple regression. Testing and interpreting interactions. Newbury Park: Sage.

American Psychological Association. (2002). Ethical principles of psychologists and code of conduct, from www.apa.org/ethics/code2002.pdf

Bargh, J. (2006). What have we been priming all these years? On the development, mechanisms, and ecology of nonconscious social behavior. European Journal of Social Psychology, $36,147-168$.

Bargh, J., \& Chartrand, T. (2000). The mind in the middle: A practical guide to priming and automaticity research. In H. T. Reis \& C. M. Judd (Eds.), Handbook of research methods in social and personality psychology (pp. 253-285). NY: Cambridge University Press.

Brown, K., \& Ryan, R. (2003). The benefits of being present: Mindfulness and its role in psychological well-being. Journal of Personality and Social Psychology, 84, 822-848.

Brown, K., Ryan, R., \& Creswell, J. D. (2007). Mindfulness: Theoretical foundations and evidence for its salutary effects. Psychological Inquiry, 18, 211-237.

Deci, E. L., \& Ryan, R. (2008). Facilitating optimal motivation and psychological well-being across life's domains. Canadian Psychology, 49, 14-23.

Dijksterhuis, A., Aarts, H., \& Smith, P. K. (2005). The power of subliminal: On subliminal persuasion and other potential application. In R. Hassin, J. Uleman \& J. Bargh (Eds.), The new unconscious (pp. 77-106). New York: Oxford University Press.

Fazio, R. H., \& Olson, M. A. (2003). Implicit measures in social cognition research: Their meaning and use. Annual Review of Psychology, 54, 297-327. 
Hassin, R., Uleman, J., \& Bargh, J. (2005). The new unconscious. Oxford, UK: Oxford University Press.

Hodgins, H. S., Yacko, H., \& Gottlieb, E. (2006). Autonomy and Nondefensiveness. Motivation and Emotion, 30, 283-293.

Langer, E. (1989). Mindfulness. Reading, MA: Addison-Wesley.

Lévesque, C., \& Brown, K. (2007). Mindfulness as a moderator of the effect of implicit motivational self-concept on day-to-day behavioral motivation. Motivation and Emotion, 31, 284-299.

Lévesque, C., \& Pelletier, L. G. (2003). On the investigation of primed and chronic autonomous and heteronomous motivational orientation. Personality and Social Psychology Bulletin, $29,1570-1584$.

Radel, R., Sarrazin, P., \& Pelletier, L. G. (2008). Intrinsic Motivation Priming via Implicit Auditory Perception. Paper presented at the $20^{\text {th }}$ annual convention of the American Psychological Science, Chicago, May 22-25.

Reeve, J. (2002). Self-determination theory applied to educational settings. In E. L. Deci \& R. M. Ryan (Eds.), Handbook of Self-Determination. New York: Rochester University Press.

Weiner, B. (1992). Human motivation: Metaphors, theories, and research. Newbury Park, CA: SAGE.

Wild, C. T., Enzle, M. E., Nix, G., \& Deci, E. L. (1997). Perceiving others as intrinsically or extrinsically motivated: Effects of expectancy formation and task engagement. Personality and Social Psychology Bulletin, 23, 837-848. 


\section{Footnotes}

${ }^{1}$ This study did not use informed consent prior to the experiment as the present research required that participants be absolutely unaware of the presence of any experimental manipulations. According to the American Psychological Association's ethical code (2002), we overrode the use of an informed consent as research did not assume to create any distress or harm and involved a study inside a natural context of teaching. To prevent any potential influences of the manipulation, the content of the course was given back after the class and was avoided in the regular end of semester exam. In addition, no false information was given to participants in order to limit their deception.

${ }^{2}$ French words were used as prime. Here, we indicate the English translation of the original words. 
Table 1:

Descriptive statistics of the main variables depending on the priming condition

\section{Priming condition}

Controlled motivation Autonomous motivation

\begin{tabular}{ccccc} 
& $M$ & $S D$ & $M$ & $S D$ \\
\hline Regular performance & 9.42 & 2.03 & 9.18 & 2.10 \\
Test performance & 5.37 & 1.80 & 6.07 & 2.35 \\
Mindfulness & 3.10 & 0.63 & 3.04 & 0.67 \\
\hline
\end{tabular}




\section{Figure Captions}

Figure 1: Performance at the post-lesson exam as a function of primed motivational orientation and mindfulness. 


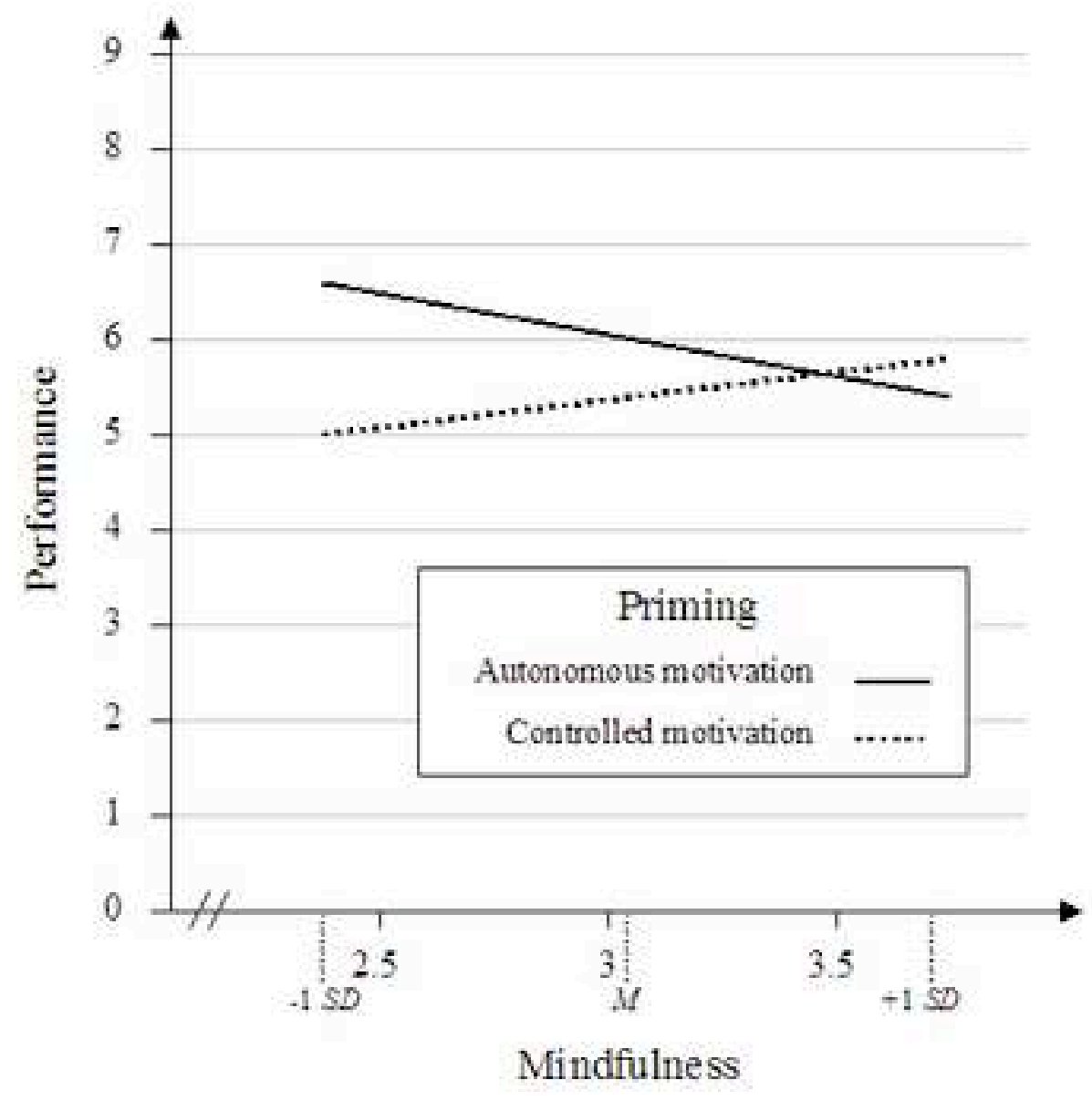

